Original research paper

\title{
Curating complexity: An artful approach for real-world system transitions
}

\author{
Stephan Kampelmann ${ }^{\mathrm{a}, \mathrm{c}}$, Michael Kaethler ${ }^{\mathrm{b}, \mathrm{c}, *}$, Adrian Vickery Hill ${ }^{\mathrm{c}}$ \\ ${ }^{\mathrm{a}}$ Université libre de Bruxelles (SBS-EM/DULBEA) and Universität Stuttgart (ILPOE), Avenue F.D. Roosevelt 50, 1050 Brussels, Belgium \\ ${ }^{\mathrm{b}}$ Katholieke Universiteit Leuven, Kasteelpark Arenberg 1, 3001 Leuven, Belgium \\ c OSMOS, Jacob van Lennepkade 205 H, 1054ZP Amsterdam, Netherlands
}

\section{A R T I C L E I N F O}

\section{Keywords:}

Complexity

Curating

Sustainability

Systems

Participation

Transitions

Trans-disciplinary approaches

\begin{abstract}
A B S T R A C T
This paper puts forward a 'curatorial approach' to systems transitions, which is a novel, practical and transparent way to deal with participation in complex and conflictual contexts. We argue that the complexity of transitions cannot be adequately addressed through traditional analytical tools. Alternatively, we propose an approach that can engage with multiple ways of knowing and expression, sustaining and developing a sense of 'meaning' in the planning process. We situate this within a systems perspective that combines individual and structural actions for vision creation. This is explored in the case study of a large peri-urban asset in Rome.
\end{abstract}

"esperti locali ed internazionali

sono stati i nostri canali

imprese e cittadini

nel lavoro sono stati vicini

terra, acqua e sole

più fatti e meno parole"

Fragment of a poem composed by participants during the workshop in Rome.

\section{Introduction}

This paper is concerned with a particular aspect of cities' efforts to become more sustainable. Indeed, these efforts are invariably confronted with a high degree of complexity that "transformative change towards sustainability" (Fischer-Kowalski and Rotmans, 2009) typically entails. This complexity poses enormous challenges to both practitioners and scholars of sustainability transitions and requires innovative approaches and methods such as the one developed in this paper.

The complexity of cities' transitions towards sustainability can be linked to two drivers of complexity. The first driver is the fact that these transitions typically involve complex interactions between social, economic and environmental phenomena that each follow distinct mechanisms. The literature on Transition Management (Loorbach, 2007) increasingly recognizes that the social, economic and environmental aspects of urban transitions are interdependent; in other words, the biophysical aspects of sustainability

\footnotetext{
* Corresponding author.

E-mail addresses: stephan.kampelmann@ulb.ac.be (S. Kampelmann), michael.kaethler@kuleuven.be (M. Kaethler), adrian@osmosnetwork.com (A.V. Hill).
} 
transitions cannot be analysed and addressed independently from anthropogenic factors. This has led to interdisciplinary concepts such as 'social-ecological trajectories' of cities (Dietz et al., 2003; Barles, 2015). In this perspective, sustainability transitions are framed as deliberate efforts to change the configuration of 'social-ecological systems'.

A second, arguably less documented driver of complexity stems from the fact that social-ecological systems differ fundamentally from the type of systems analysed by the natural sciences. The crucial difference between, say, the ecosystem of a natural forest and the social-ecological system of an urban neighbourhood is that the latter cannot be analysed independently from the meaning that the communities of the neighbourhood attach to their environment; indeed, these communities are at the same time the object and the subject of system thinking. As a consequence, any approach to social-ecological trajectories that does not allow to tap effectively into the interpretations and significations of the involved actors is likely to fail (Segers et al., 2013).

The combination of these two drivers of complexity poses an interesting problem to planning professionals and transition researchers. On the one hand, they have to find ways to engage with actors in order to mobilise their personal interpretations of the current situation and to co-create potential trajectories towards sustainability. But, on the other hand, this engagement is unlikely to produce constructive results if the planning professional or transition researcher does not bring his or her own personal interpretation and analytical lenses into play, for instance by framing the interactions with actors in terms of system thinking and social-ecological transitions.

This paper proposes to overcome the ambivalence of this position by transposing the role of the curator from the art world to planning situations. A curator-planner is not neutral but cares for the subject matter and proposes her own interpretation of the social-ecological system and its potential trajectories, notably by framing the planning problem in an oriented, meaningful way. At the same time, a curator-planner cannot impose this interpretation onto the audience but rather aims to solicit personal reactions and engagement.

We have developed this idea into a 'curatorial approach to system transitions', which we think is a novel, practical and transparent way to deal with stakeholder participation when planning for sustainability transitions. This paper describes the theoretical basis of this approach and presents empirical evidence from its application to a real-world sustainability transition related to the governance of a large urban asset in the city of Rome.

The paper is structured as follows. In Section 2 we present three problematic qualities evident in urban planning situations that give rise to complexity and link them to three guiding principles of our curatorial approach. We further present the process method of this approach. Section 3 describes a case study in which we applied this process to a participatory planning problem related to the Parco Agricolo Casal del Marmo in the Lazio region in Italy. We notably describe the context of this case, the implementation of the curatorial cycle and the main results of a participatory workshop. Section 4 discusses results and Section 5 reflects on the approach and concludes.

\section{Capturing complexity of wicked problems}

According to Frantzeskaki et al. (2017), numerous cities around the world have started to experiment with "structural systemic realignments" in order to become more sustainable. Frantzeskaki et al. refer to these experiments as "urban sustainability transitions". A key insight from the literature on Transition Management is that such urban sustainability transitions resemble "wicked problems' (Fischer-Kowalski and Rotmans, 2009). According to Rittel and Webber (1973), wicked problems are found in societal contexts involving issues such as environmental, economic, or public policy within a pluralistic society where there is no objective definition of a public good. Churchman (1967) has described such problems as "ill-formulated, where the information is confusing, where there are many clients and decision makers with conflicting values".

The presence of multiple types of knowledge and actors in urban sustainability transitions requires adopting multiple overlapping perspectives as any specific discipline or body of knowledge will always be partial and provisional (Checkland and Scholes, 1990; Brown et al., 2010; Midgley, 1991; Moulaert and Van Dyck, 2013). Key elements of the transition process - its actors and their knowledge - are not exogenous to the analysis. They can for instance decide on the goals and the rules of the process and, on a more fundamental level, assign meaning to the transition. The curatorial approach we present in the next section offers an innovative and conscious effort to place the researcher within the interpersonal dynamics that are part of the planning situation.

\subsection{The curatorial approach to systems transitions}

While much has been written about potential tools for tackling complex or 'wicked problems', considerably less is written about influential roles that can facilitate these, as individual approaches or assemblages, within a participatory setting (Head and Alford, 2015; Weber and Khademian, 2008). Roles like organiser, facilitator, or moderator tend to reflect the logic of tame problems that can be 'fixed' through analytical decomposition guided by the actions of a neutral actor. These roles are borne out of, and carry with them, tools, logics and institutional baggage (Van den Broeck, 2011) from fields such as business, politics and game theory. With this in mind, we argue instead for a curatorial role, a position that deals with complexity and conflict using multiple approaches, methods, logics-one that identifies itself as part of the actor cohort and is deeply concerned and connected with the content. While roles like mediator and facilitator value the qualities of 'neutrality' between parties or 'disinterest' in specific outcomes, the curator takes the contrary position. We think that it is mainly in this respect that our curatorial approach provides additional mileage to the literature on Transition Management. The latter has stressed the importance of actors in achieving deliberate changes in complex systems and, among other issues, investigated which type of governance set-up allows social-ecological systems to be more adaptive (FischerKowalski and Rotmans, 2009; Loorbach et al., 2016). One of the key foci in terms of how different types of actors influence 
sustainability transitions has been the idea that frontrunners, or pioneers, operate in "niches" where they develop new sociotechnical solutions to sustainability challenges. In the Transition Management literature, the researcher herself is not seen as a frontrunner, but she can help to understand and to influence the conditions in which niche experiments and their up-scaling towards societal solutions can thrive (Rotmans et al., 2001; Geels and Schot 2007). In the curatorial perspective, the researcher-curator has arguably a more proactive role in shaping the outcome of practical interventions on the ground. In this sense, the curatorial approach is a way of understanding the transition researcher not only as an analyst and facilitator of frontrunner-driven experiments, but also as an essential role for providing interpretations and meaning.

The Swedish curator Maria Lind (2010: 63) defines the curatorial, as “...a way of thinking in terms of interconnections: linking objects, images, processes, people, locations, history and discourses in physical space like an active catalyst generating twists, turns and tensions." In today's art and design world, the curator plays an important role as translator and mediator (Kaethler, 2016) between the artefact and different audiences. She is intimately connected to the artefact itself and deeply concerned with the output of the translation, actively giving it form but plays a role, which is neither the cultural producer nor the audience (Lind et al., 2010; O'Neill and Wilson, 2010; O'Neill, 2012; Smith, 2012). It can be characterised as a “distinct practice of mediation" as Paul O'Neill (2012) argues, with exhibitions acting as a "coproductive, spatial medium, resulting from varying forms of negotiation, relationality, adaptation, and collaboration between subjects and objects, across space and time.” Likewise, Hans Ulrich Obrist (2011), the prolific Swiss curator refers to the role of the curator as "connecting different people and practices, and causing the conditions for triggering sparks between them." The curator, having been provided with institutional or cultural legitimacy, makes use of a broad arsenal of communicative techniques for engaging audiences (Martinon 2013).

In recent years curating has been applied to diverse fields, as taxonomical cataloguing in health care (Rubin, 2008; Lynn et al. 2010; Glasner et al., 2006), data organisation and classification (Dahdul et al., 2010; Goble and De Roure, 2008; Witt et al., 2009) and pedagogy (Webb et al., 2013; Gallagher and Wessels, 2013; Eeds and Peterson, 1991). The common thread is the combination of complexity and signification. Yet the planning field has yet to fully embark down the curatorial path. Participatory planning approaches often place the emphasis on problem solving through practical or analytical methods with less consideration or focus on developing new meaning around relationships (social and socio-technical) or artefacts (Segers et al., 2013; Loeckx, 2004). Discourses on coproduction (Albrechts, 2013; Miciukiewicz et al., 2012; Mitlin 2008; Hamdouch and Moulaert, 2006; Ostrom, 1996; Swyngedouw, 2005) and meta-frameworks for the co-creation of theory (Moulaert et al., 2011; Moulaert and Van Dyck, 2013; Khan et al., 2013, 2014; Segers et al., 2013) resonate with curatorial principles-namely, the utilisation of multiple forms of input, media and stimuli along with the recognition, acceptance or instrumentalisation of subjectivities, such as 'meaning' or significance systems in order to bridge difference. Planning-based metaframeworks, such as constructed by the SPINDUS project (Segers et al., 2013) recognise that the context cannot be analysed independently from the meaning that the communities of that context attach to it-creating an interwoven co-production of knowledge-and-values. This focuses on the action or process itself and not on the particular role and ethos of the facilitator. As Metzger (2013) stresses, the facilitator engages with 'reality crafting', and refers to what Charis Thompson (2005) describes as 'ontological choreography'. The curatorial thus adds a unique perspective to participatory planning, challenging how it perceives certain roles and how it deals with knowledge production.

\subsection{Three guiding principles of our curatorial approach}

We argue that framing urban planning situations as wicked problems and adopting a curatorial approach with systems at its heart, provides considerable mileage for untangling stand-offs and making such problems accessible to relevant actors. In effect, this implies a re-framing of the role of facilitator as a creative knowledge broker, mediating, translating, positioning and choreographing different types of knowing. This can be derived by looking at three guiding principles that characterise our curatorial approach to system transitions: 1) focusing on 'meaning', 2) activating multiple ways of knowing (including non-cognitive), and 3) moving between the particular and the whole. To be sure, these three principles are not entirely novel and issues related to one or several of them have been previously raised in the literature concerned with transdisciplinary approaches to co-creation processes with stakeholders. This being said, the work presented in this paper nevertheless fills a gap in this literature by addressing all three principles in the same framework and by linking them to a particular response to them, i.e. the curatorial approach.

Below, we explore how these 3 characteristics of our curatorial approach address key problematic elements in systems transitions-knowledge, actors and scales.

Knowledge. The curatorial affirms that there are multiple ways of knowing and articulating knowledge. Curating has a long tradition of handling different forms of knowledge, often simultaneously, that range between the 'non-objective' found in artistic processes to conceptual, analytical and strategic such as with writing theoretical texts, the running of gallery spaces and budgets (Acord, 2010). The role does not reduce knowledge to a hierarchy, instead its strength is found in pulling together the multiple ways of knowing to form an installation or exhibition that communicates complexity in a coherent form (Smith 2012).

Working with artefacts and creative producers on one hand and audiences on the other requires a careful translation of meaning between a wide range of actors each with diverse epistemologies and ontologies. The curatorial role does not create an interdisciplinary interpretation for the different actors; it provides a platform for understanding where different types of knowledge partake and share in that particular experience. This renders knowledge as a process and not as an object, which is separable from knowers, but as socially constructed and embedded in situ and practice (Brown and Duguid, 2001). In other words, knowledge is more than information, it is socially negotiated meaning, contingent on those who are involved and tightly tethered to the context (Syed-Ikhsan and Rowland, 2004). This experience is carefully crafted and involves a spectrum of forms of communicating, appealing to a holistic sense-making. 
This collation of different forms of knowing and expression is made meaningful and real through processes of reification, which is the translation or congealing of ideas into 'things' such as artefacts, relationships or even into concepts such as 'justice' (Lave and Wenger, 1991; Gherardi and Nicolini, 2000). The materiality or concreteness involved provides a milieu for inquisition and exploration enabling negotiations among participants with unique or diverse interests and skills. This results in an artefact such as a sketch, a plan or design that represents the moment of codification when the knowledge of the group is synthesised into a material/ symbolic system which in turn embodies a new context of use and thus also a new starting point within an on-going process upon which dialogue is sustained.

Actors. Planning processes involve a wide range of actors that have to be concerted, convinced or consulted. There has been a surge in tools and methods designed for facilitators to select and integrate many of these actors in planning processes, most recently under the banner of 'Participatory Design Workshops' (Cox et al., 2014). Most of these tools have led to disappointing results. For example, actors are involved at a moment where they can contribute little to the ultimate outcome or overstrained time and resources of different groups results in 'participation fatigue' (Kaszynska et al., 2012). There is also a more general concern that a focus on 'key actors' overemphasises economic and political power over alternative criteria such as being personally affected by the planning processes, professional and lay knowledge about the site or civic leadership in the concerned area. Jonathan Metzger's (2013) perspective on the subjectivities of becoming a stakeholder emphasises the importance of the development of an attachment with the context. Individual subjectivities are not extraneous from the negotiation process but are what Metzger (2013) refers to as "a specific 'produced' mode of action and thought established through investments and efforts", a type of 'relational effect' as opposed to an 'ontologically given property'. In this, Metzger identifies the importance of 'developing', or as this paper suggests, curating, the conditions, which may bring about a 'collective becoming'. These conditions can be engendered and prompted by individuals within a planning process, as we emphasise, by a curatorial role, which aims to specifically develop a personal attachment.

We argue that taking a disinterested position as neutral facilitator does a disservice to the context, rendering analysis and propositions as scientific, concerned more with what 'is' than what 'could be' and limiting the different means to explore the problem and possible solutions. In contrast, the role of a curator situates the organiser's role as deeply 'caring' for the context and its outcome. The term curator originates from the latin cura, to care for. The role of the curator, originally, was a caretaker of objects and artefacts and today the curator is concerned with what the artefacts 'mean' to different audiences. We propose both of these roles, a deep consideration and care for the social-ecological context and its potential futures as well as translators-helping communicate the context's meaning according to local stakeholder positions and our own position. This entails adopting strategies that aim to penetrate below the levels of 'interest' and 'position' and include addressing emotive and experiential facets of actors through visual, creative, experiential and reflective modes of action. As such, we avoid questions of leadership in favour of individual and collective experience by providing short intensive moments that instigate an unbinding of previously entrenched positions on the specific subject matter.

By focusing first and foremost on the subjectivities and inter-subjectivities of actors, the curatorial approach aims to initially bypass the politics of negotiation, which inevitably follows. It circumvents an explicitly political dimension, instead, trying to dig deeper than interests and positions to forms of signification, similar to that of the art world. The interest is first and foremost to develop a connection between the individual actor and the specific context. The development of new meaning can transcend old antagonisms because it is more malleable than hard pecuniary interests. Additionally, these moments of signification are intended to be de-politicised moments, times of individual or collective reflections and discussions, encouraging formerly antagonistic positions to speak to one another as humans. ${ }^{1}$

Scales. Changing urban form typically affects functioning at multiple scales. Scales are deeply intertwined so that interventions at a particular scale need to understand and anticipate interrelationships with smaller and larger scales (Spangenberg et al., 2002). Moreover, without a nuanced understanding of the different nature of scale levels, policy-making can easily become fragmented and inconsistent resulting in confusion and distrust (Swyngedouw, 2005). These can also be interpreted as scales involving time, ranging between the immediate and long-term futures of the space, relationships and roles or responsibilities. This complexity constitutes one of the core themes of the planning profession and has inspired visual and conceptual tools to address multi-scalar problems. However, in practice, planners face time constraints and relatively narrow mandates so that multiple scales often continue to be a poorly resolved issue.

As any exhibition will demonstrate, it is composed of a series of artefacts, which, when 'put in dialogue with each other' unlock new meanings (Smith, 2012) working together to form a single experience. The whole experience cannot be divorced from the individual artefacts, which are carefully composed, arranged, and articulated. Dan Hill (2012) refers to this as skipping between the 'meta' (the big picture) and the 'matter' (the material detail). Taking from the curatorial and systems thinking tradition, we contend that the particular and the whole cannot be understood without the other, therefore, moving towards systems transitions requires change to occur at the individual and structural levels. The curatorial draws the agency from the individual level into the systems level, this oscillation of scales enables a view of actants as networked and not severed across scales.

\footnotetext{
${ }^{1}$ The authors of the paper acknowledge the highly political nature of complex actor negotiations and recognise that further research and discussion is necessary for bridging the curatorial approach with the politicisation of the negotiations.
} 


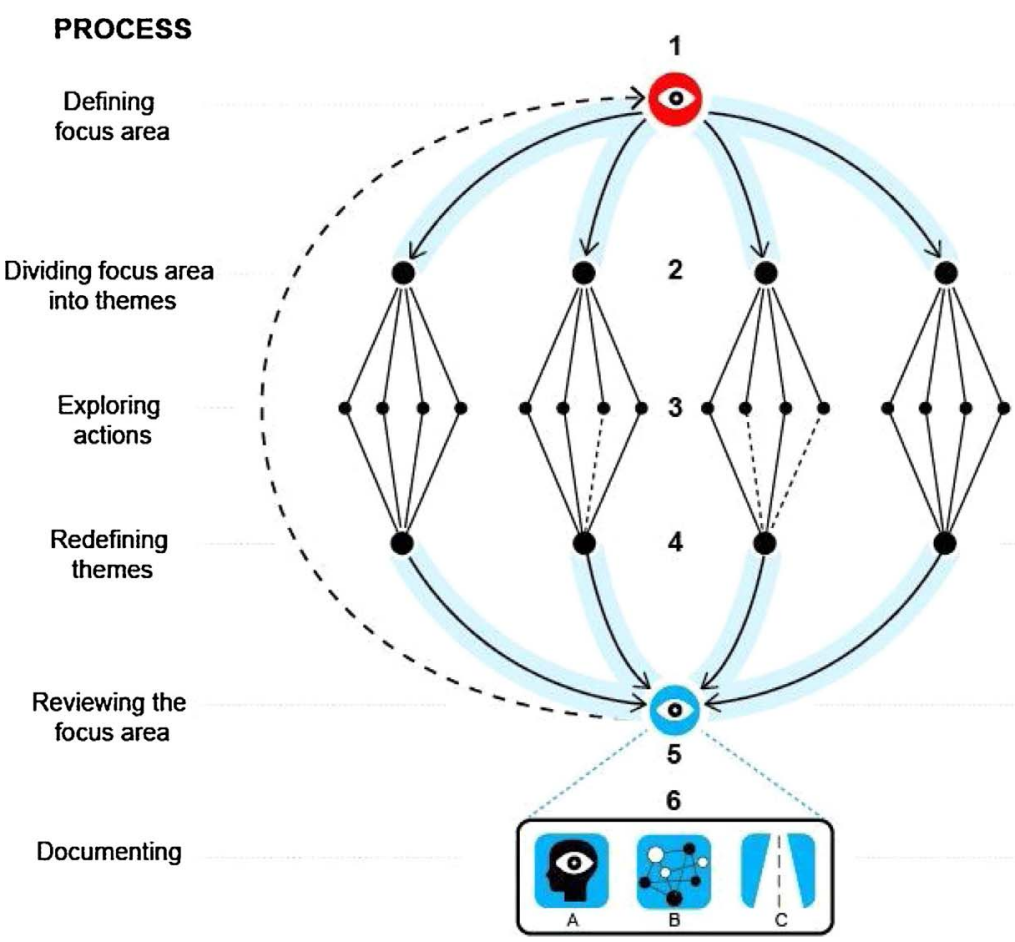

\section{CURATORIAL INTENTION}

Framing

\section{Engaging \\ through \\ signification}

Rechanelling

Reframing

Positioning

Fig. 1. The workshop cycle; the curatorial frames the steps in the process

\section{Methodology and case study of the curatorial cycle}

\subsection{Methodology}

To best explore the curatorial approach, we employed an action research methodology, which is steeped in a desire to bridge academia with other worlds with the intent of addressing a problematic issue and changing it for the better with the communities involved benefiting from the research (Kindon et al., 2007). To do so, partnerships with local organisations were key in developing the approach and continued to shape it during the event and afterwards in moments of reflection. Moreover, we felt the best way to explore the approach was to execute it and observe its results. Applying it to the context of the Parco and then, following Kemmis and McTaggart's (1988) model: plan, act, observe and reflect. This implies considerable reflexivity in the planning and execution of the approach, resulting in the authors being part of the cohort and situation that was studied. Additionally, the authors looked to other actors for input, rendering the research a collaborative endeavour. The reflections of the workshop are based on the experiences of the authors as well as the input from 4 partner institutions, 7 international experts who took part, written feedback from over 40 attendees, a report from the hosting NGO and an independent report from a professor of social-psychologist who attended.

\subsection{Process: the curatorial cycle (the workshop structure)}

Our curatorial approach aims to limit what are commonly long and drawn out 'negotiations' over entrenched stakeholder positions within a workshop structure. Given the time constraints involved in short-term workshops we frame scenarios as interventions, creating a spatial/temporal break, disrupting habitual patterns of thinking on the subject matter. We seek to use features such as time and risk as an intrinsic part of the workshop - a compressed multi-experiential event evoking strong emotions, memories, ideas, and beliefs. In this way discussions can be much more frank, open and direct (Fig. 1).

The workshop is designed as a cycle consisting of six steps. The first step (1) opens up the discussion and frames the focus area. The following three steps (2-4) involve splitting the focus area into smaller themes that invokes emergent thinking (deals with specific problems, tests concepts, explores action areas). The fifth step (5) uses knowledge gained in steps 2-4 to review the focus area through an exhibition of the work produced (themes are compared and the vision tested). These five steps are what we, in the context of a workshop, call a curatorial cycle, which can occur numerous times over the course of the workshop. Once the general focus area has been defined, it is possible to refine a vision and define specific actions. The final step (6) involves documenting the process and defining steps forward. Table 1 below summarizes the process, curatorial intention and expected outcome for each of the six steps of the curatorial cycle. 
Table 1

Process, curatorial intention and outcome of the six steps of the curatorial cycle.

\begin{tabular}{|c|c|c|c|}
\hline & Process & Curatorial intention & Outcome \\
\hline Framing & $\begin{array}{l}\text { to begin bringing together different } \\
\text { ideas, worldviews, hopes and fears. }\end{array}$ & $\begin{array}{l}\text { to start with the holistic vision of problem area, } \\
\text { which is a curated working hypothesis. This is } \\
\text { the basis for exploration using different means } \\
\text { available, such as artefacts, images, research } \\
\text { material or presentations, which set the tone } \\
\text { without directly addressing the specific context. }\end{array}$ & $\begin{array}{l}\text { The basic building blocks of a coordinated } \\
\text { vision that allow for discussions to funnel } \\
\text { towards specific issues. }\end{array}$ \\
\hline Channelling & $\begin{array}{l}\text { Break down the vision of the problem } \\
\text { as a system composed of multiple } \\
\text { tangible problems, which can be } \\
\text { individually addressed. }\end{array}$ & $\begin{array}{l}\text { to predefine the themes before the workshop in } \\
\text { order to channel the focus of the participants. }\end{array}$ & $\begin{array}{l}\text { Participants are not lost within the } \\
\text { complexity of breaking down a large } \\
\text { problem. Instead, this activates discussions } \\
\text { and accelerates the collaborative process } \\
\text { towards pre-determined useful themes. }\end{array}$ \\
\hline $\begin{array}{l}\text { Engaging through } \\
\text { signification }\end{array}$ & $\begin{array}{l}\text { to personally reflect and identify } \\
\text { concrete actions, artefacts or } \\
\text { conditions for addressing a part of the } \\
\text { problem. }\end{array}$ & $\begin{array}{l}\text { to create the conditions for individuals or small } \\
\text { sub-groups to personally identify with the } \\
\text { problem or solution and to find a unique voice } \\
\text { within the wider discussions. }\end{array}$ & $\begin{array}{l}\text { The emergence of specific action points for } \\
\text { a small part of the larger problem. }\end{array}$ \\
\hline Rechannelling & $\begin{array}{l}\text { Integrate different particular } \\
\text { solutions within a larger body of } \\
\text { solutions. }\end{array}$ & valorising leverage points. & $\begin{array}{l}\text { A deepened knowledge of how the } \\
\text { particular parts fit within the whole. }\end{array}$ \\
\hline Reframing & $\begin{array}{l}\text { Bring the groups to a point of } \\
\text { exchange to review and refine the } \\
\text { vision. }\end{array}$ & $\begin{array}{l}\text { Negotiation of knowledge(s) through bringing } \\
\text { together tensions, juxtapositions, } \\
\text { complementarities et to catalyse responses and } \\
\text { resonance with the proposed vision. }\end{array}$ & $\begin{array}{l}\text { A closer consolidation of particular } \\
\text { proposed solutions within the vision. }\end{array}$ \\
\hline Positioning & $\begin{array}{l}\text { Document and communicate the } \\
\text { ideas from the previous steps into a } \\
\text { meaningful and memorable form. }\end{array}$ & $\begin{array}{l}\text { To support multiple voices and expressions in } \\
\text { translating different ideas into a visual } \\
\text { representation. }\end{array}$ & $\begin{array}{l}\text { a visual representation that incorporates the } \\
\text { complexity of the problem and the nuances } \\
\text { of the multiple solutions provided. }\end{array}$ \\
\hline
\end{tabular}

\subsection{Curating a system transition in the parco agricolo casal del marmo}

The area referred to as Parco Agricolo Casal del Marmo is a 460 ha site situated in the North-West of Rome, historically used for agricultural purposes. Most of the Parco has been left fallow since the 1970's real estate speculation (Suchiarelli, 2002) and today, only a small area serves as pasture for local sheep (overseen by a cooperative). The Parco is bordered by several peripheral neighbourhoods of the city of Rome and a hospital. Public authorities own approximately one fourth of the area; the rest is split between various private and ecclesiastical latifundistas and a commercial bank. The entire area has been earmarked as a 'collective interest area' in land use planning as agricultural park - a political decision that translated into a considerable financial loss for landowners willing to develop the land (Bollettino Ufficiale della Regione Lazio, 2014).

In October 2014, the authors were approached by the regional public business innovation agency (BIC Lazio) and the local municipality (Municipio XIV Roma Capitale) to consider the Parco Agricolo in the context of our work on TURaS, a European research project on sustainable and resilient cities. The situation fit Rittel's description of a wicked problem. Firstly the problem statement was ill-formulated since it was unclear what the actual task or question was that we were supposed to examine. Information was confusing because local actors possessed numerous layers of often incommensurate knowledge about the site, including outputs of previous participatory planning actions for the site (Associazzone Comitato per il Parco di Casal del Marmo, 2012). There were likewise many clients and decision makers with conflicting values; we were asked to work with local and regional agencies with different agendas and interests in the site and also had to consider a wide range of other private actors such as the landowners. Part of the local business community and civil society also has (potential) interest in the development of the Parco. Finally the ramifications of a project at such a large scale within the political and economic hub of the city of Rome, with implications for social and natural systems at different scales, struck us as truly perplexing - or wicked. We therefore decided to frame the situation as a wicked problem and apply the above-mentioned principles of the curatorial approach to system transitions in order to help creating a future for the Parco.

\subsection{Applying the curatorial cycle in a three-day participatory workshop}

In this section we describe how we applied the curatorial cycle described in Fig. 1 to the 'wicked problem' we faced at the Parco in a three-day, on-site, hands-on workshop with around 60 participants from the area that was organised in June 2015 . The overall architecture of the workshop, which was highly flexible in its design, was based on the six steps of the curatorial approach presented above. During the three-day workshop we completed two full cycles: after finishing Step 5 in the morning of Day 2, we started again with Step 1 (Fig. 2).

Step 1. Framing. In curating art, framing is essentially indicating 'look here' 'this is important', it implies translating what is essential and emphasising this to the viewer by selecting what to experience and staging it in a way that guides how they experience it. In the curatorial approach, the curators took the liberty to frame the discussion on land governance by focusing it on 'finding a sustainable future for the Parco Agricolo'. In doing this, it avoided attempts at neutrality as well as being bogged down in preliminary 


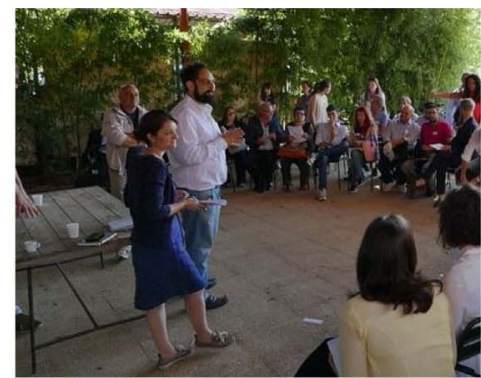

Step 1. Framing

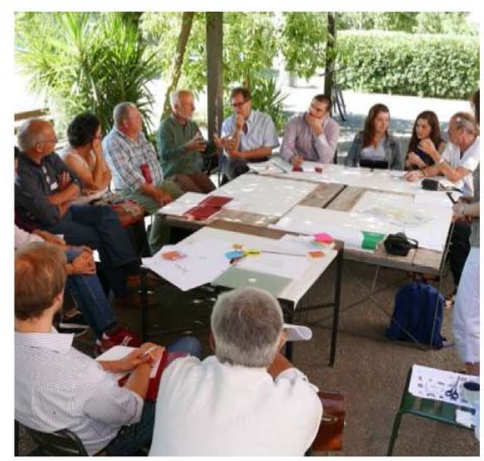

Step 4. Rechanneling

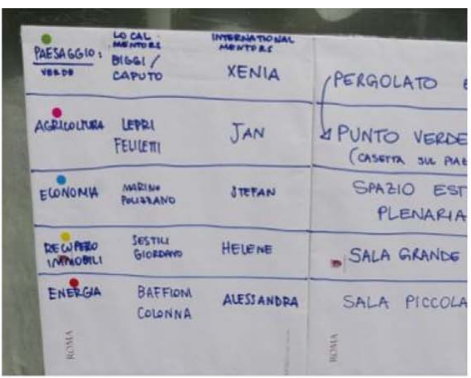

Step 2. Channelling

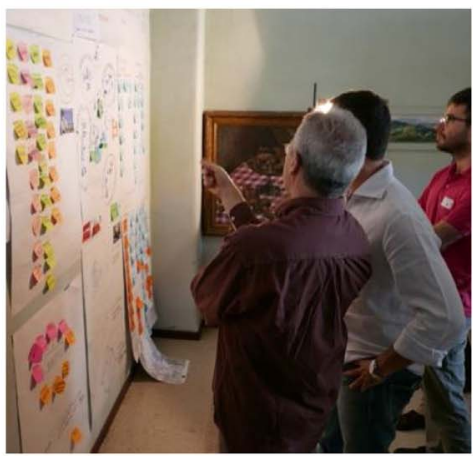

Step 5. Reframing

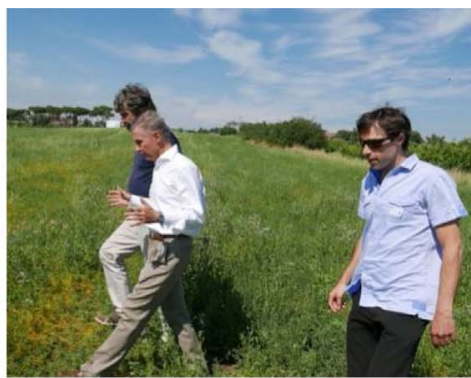

Step 3. Engage via signification

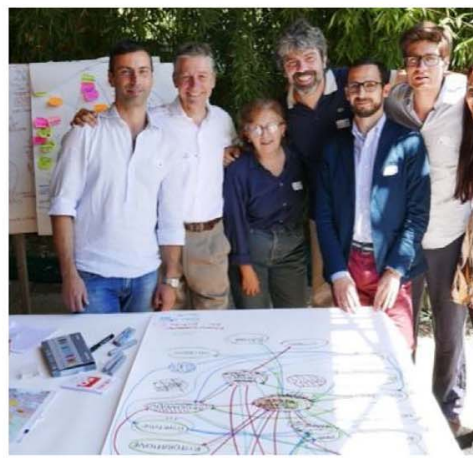

Step 6. Positioning

Fig. 2. Workshop steps.

discussions related to actor interests. We clearly stated in all communications that the purpose of the workshop was to "create a community-based food system" of which the Parco was to be the heart. This reflected our intention and values in favour of a more localised food economy and the importance we attach to community-based development. As such we embraced a non-neutral political stance, which was based on the narrative, which arose through initial discussions and co-constructing exercises with local actors. We learned that land such as the one at the Parco is exposed to strong economic pressure from the housing market, which tends to turn arable plots in peripheral locations of metropolitan areas into allotments of suburban dwellings for commuters (as has occurred in surrounding areas). We wanted to suggest to the local and regional decision makers that the Parco could play a completely different role in the urban system. While the representatives of the local municipality shared our non-neutral assessment from the beginning, we further curated the narrative to help narrow the problem area by giving a specific starting point from which to move forward. We will not argue in this paper whether this vision was justified, but rather show how we incorporated it in our curatorial approach.

How this message was experienced came in the form of the process, which integrated experiential and mimetic moments with linear thinking and planning activities. These latter activities took the form of applying systems thinking to community-based food system in the Parco (see stages 2 and 4). The experiential and mimetic was applied through a mix of visual artefacts as boundary objects, physical exposure and presentations.

We framed the workshop experience through a mix of visual artefacts, physical exposure and presentations. We prepared and exhibited on the site of the Parco an exhibition of large high quality photos with descriptions of community-based food projects of various scales (from school projects to regional initiatives) from different contexts across the globe. Many of the discussions and events occurred in or around this exhibition, acting as a backdrop and providing references, even if indirect, to other experiences we wanted to incorporate into the narrative for the Parco. These references prompted inspiration but also frustration for the participants who claimed that these types of projects are very difficult to implement in Italy due to bureaucratic, political and economic delays. Other visual stimulation came in the form of a series of provocative montaged postcards that visually illustrated various possible scenarios for the Parco that had been floated over the past several decades, such as the site of a new Ikea, a set of typical Roman apartment blocks or an amusement park.

The framing process also included a guided walk around the site that heavily emphasised current and potential agricultural uses of the Parco. This was followed by short impulse presentations that again focused on community-supported food projects in other cities (given by five external experts). Finally, the workshop brought together a collection of a vast amount of background data, reports and maps. We curated this material by emphasising references to the potential of the site as a hub for a community-based food system and made this material available prior to and during the workshop.

Neither during the first cycle on Day 1 nor during the second cycle on Day 2 the overall vision of working towards a community- 
based food system was contested. It was clear from the plenary presentation in the morning of Day 2 that most participants had already come to the workshop with similar narratives (for instance in terms of 'kilometro zero' initiatives popular in Italy) or had adopted elements of the curatorial vision during the first cycle.

The curatorial vision for the workshop was to re-align individual experiences with the Parco and to do this, it sought to provide a combination of provocations, inspirations, data and moments of reflection. The choices were based on understandings of the context and specific actors as well as on broader human themes such as a desire to connect with nature and popular local themes such as kilometre zero.

Step 2. Channelling. Step 2 involves moving from the whole to the particular. We organised participants and conversations into a limited set of themes: Steps 2-4 thus took place within thematic groups composed of 10-15 participants. Group formation was based on the municipality's assessment of each participant's knowledge, interests and professional training; participants were free to affiliate and follow other themes as well (and many did).

The themes were similar to the principles of relevance that designers identify when addressing wicked problems (Buchanan, 1992) and made reference to specialised disciplines in the arts and sciences and included agriculture, urban integration, landscape, energy and resources, and economy. These themes were set prior to the workshop by the research team and representatives from the municipality in order to save time and on-going discussion during the workshop, but also allowed a targeted recruitment of participants. ${ }^{2}$ It further allowed the collection of specific background material for each theme.

In the logic of framing the workshop as co-creating a vision for a community-based food system, each theme was framed as a subsystem. During Step 2, the groups formed by each theme were given a set of clear objectives and tools that aimed at developing systematic thinking within the group, including intermediate objectives such as "understanding system analysis", "understanding system maps", "identifying the elements of the system" etc. While the themes were somewhat elaborated for the teams, it was expected that the team validated or redefined them as they saw it.

The act of actually drawing a system, even a simple system (e.g. how a carrot travels from farm to fork) was enough to create a common vocabulary to encourage actors to participate in the map-making process. The workshop confirmed that people are rarely trained to think in systems and will clutter-up and focus on their specialisation if left to their own accord. The basic concept of systems thinking proved to be quite didactic and helped individuals to clutter-up and express their knowledge in a way that would be commensurate with other conversations.

Step 3. Engaging through signification. Step 3 is pivotal in our framework as it strives to create situations in which all three curatorial aspects come into play. Thematic groups were split into more specific issues, in groups of 2-4 individuals that would be most likely to lead to meaningful exchange on a personal level (aspect of meaning). These more intimate conversations would span a broader and deeper spectrum of human communication, and participants were encouraged to walk around the site so as to situate Step 3 in the landscape (multiple ways of knowing and rooting that 'knowing' in meaning). The conversations were framed as a midpoint of the cycle whole-particular-whole (elements within a whole).

We consider Step 3 as extremely valuable for the entire workshop process as it featured deep conversations about actions that are too often missing from other participatory approaches to planning. The diversity of situated conversations also rendered the work on each theme more resilient: while not all conversations made equal progress, having many of them simultaneously on each theme ensured that the groups could build on a diverse mix of creative, constructive, visionary, and realistic conversations. Also, as the team members could freely engage with other groups, cross-pollination of ideas allowed both collaboration and competition and propelled the groups forward.

Step 4. Rechanneling. Step 4 is the last step at theme-level and serves to redefine or update the results of Step 2. We set the objective of this step as identifying the action areas with the highest leverage for transitioning the Parco's system in the desired direction. For this purpose, overlapping conversations could be merged and irrelevant or conflicting ones discussed and discarded.

Step 4 was instrumental as a bridge between the personal conversations of Step 3 and the plenary presentation in Step 5 . We believe that the symmetric nature of the curatorial cycle allowed to keep the group-level discussions relevant and constructive: results from the personal conversations were presented as contributions to the thematic objectives as well as in the context and language of the framework that the group defined together prior to splitting.

Step 5. Reframing. This step is intended to bring all thematic groups back to the system level and allows assessing to what extent the agricultural, urban, landscape, energy and economic subsystems fit together to form a whole. At the Parco workshop this took the form of a plenary session in which a collage of visual material (including vision drawings and subsystem maps) was exhibited as a backdrop.

At the end of the first cycle, Step 5 naturally produced a rather heteroclite collage of ideas, concepts, propositions and partial visions. Presenting these elements side-by-side as a first step towards a more coherent vision nevertheless created the impression of an ensemble. The presentation of the results as a collage fostered a deep sense of ownership for both the partial results and the vision for the whole. Already after the first cycle many participants referred to the process as "our method" and the research team's main achievement as "having brought us all together so that we can work this out". By this point in the process, it was increasingly participant led, with a sense of what came up repeatedly in the interviews as 'collectivity' in the sense of the Parco as a whole and in terms of finding and implementing a "possible and healthy" solution (Fig. 3).

\footnotetext{
${ }^{2}$ In addition to the themes, we used Pentahelix actor mapping to ensure the representativity of the participants with respect to different types of actors from business, finance/capital, community, knowledge and public authority. With the exception of finance, the composition of the participants was reasonably representative.
} 

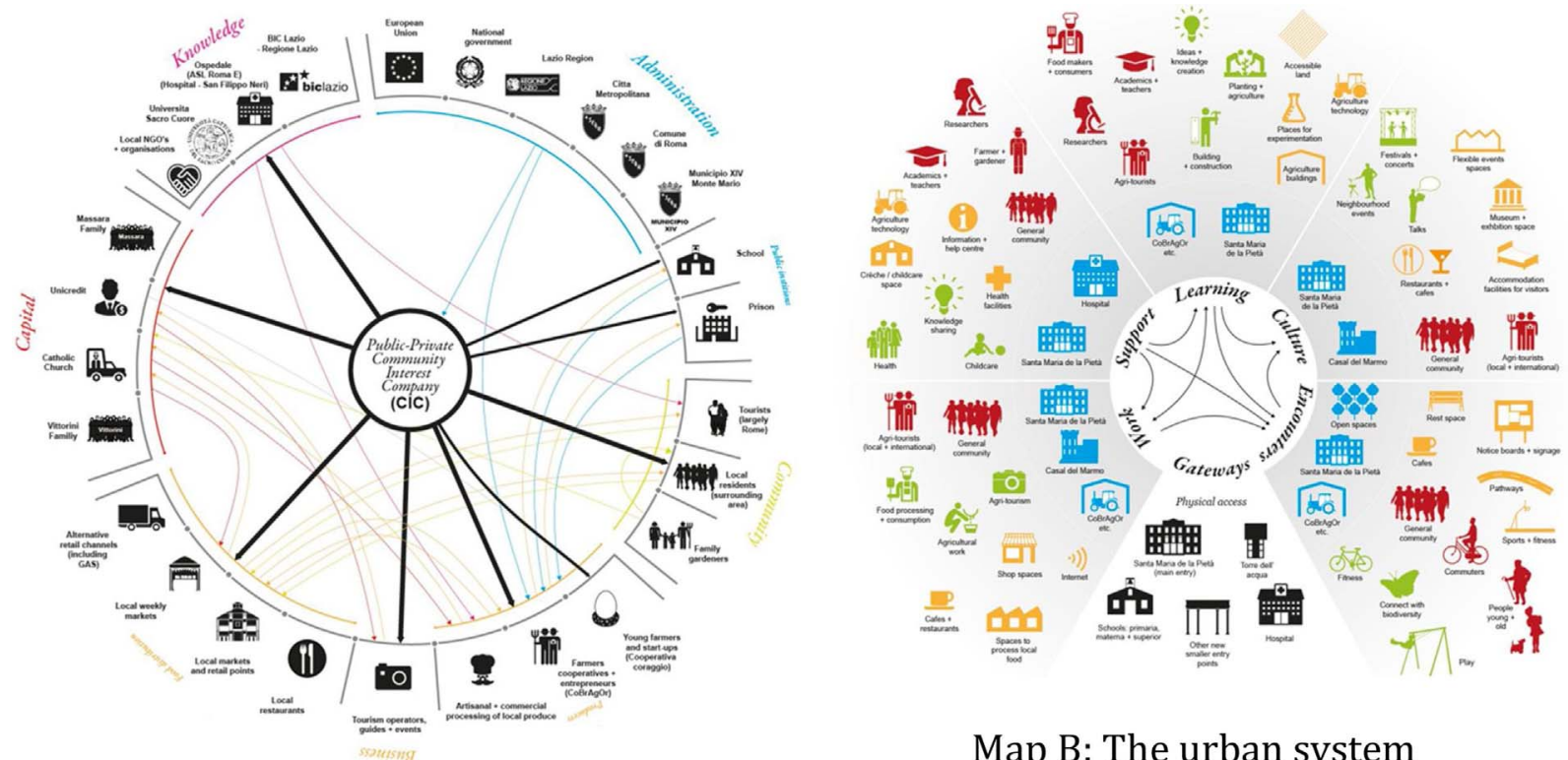

\section{Map B: The urban system}

\section{Map A: The governance system}

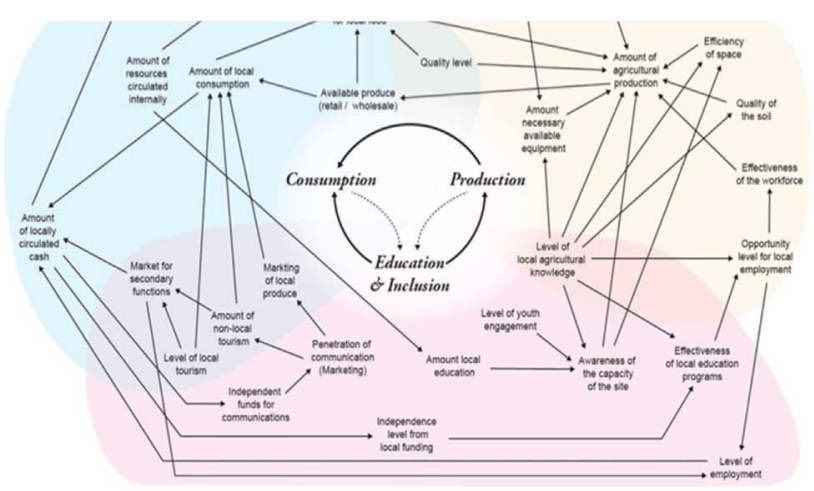

Map C: The agricultural system

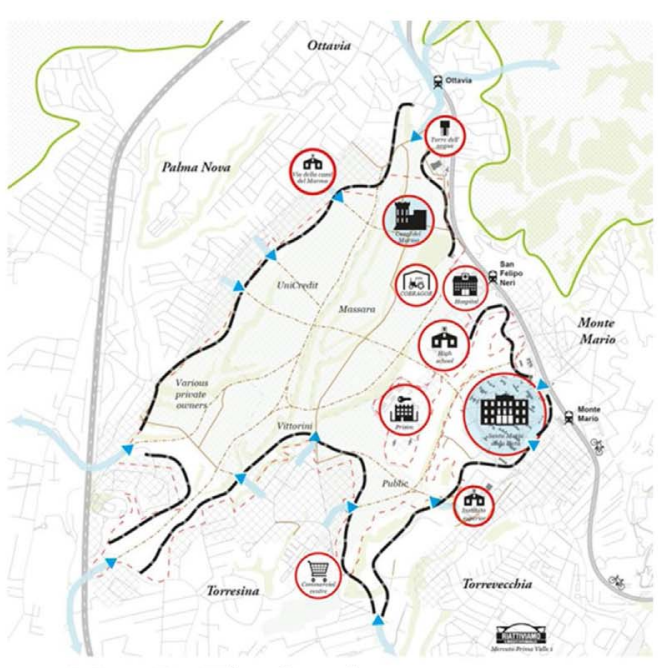

Map D: The landscape system

Fig. 3. Examples of the styles of the maps produced for the final exhibition.

Since we were able to go twice through the curatorial cycle, Step 5 was again followed by Step 1 (Fig. 2).

Step 6. Positioning. This step positions the workshop output through different elements of documentation. Fig. 4 (above) shows the range of ideas developed within the groups. This is only a sample of the output however it shows the diversity of the material developed by the participants and how they represented their ideation process. The groups were asked to include 3-5 'action areas' based on the most significant priorities - many of these were those explored during Step 3. The compilation of all of these diagrams helped define overlaps and the main leverage points for the project as a whole. In this case one of the main conclusions from the workshop was that an independent organisation, we refer to as a 'community interest company', was necessary to represent the vision, drive and negotiate change.

\section{Results}

Defining results from a complex co-creative multi-actor process is complicated and begs questions of attribution. The process of involving such a wide variety of actors in the decision-making process at such an early stage in the project was in itself considered a major result by organising partners. As our involvement was limited largely to the workshop moment the paper first focuses on the practical outcomes of the workshop. To do this, the results are presented in terms of the three aspects of the curatorial approach noted 


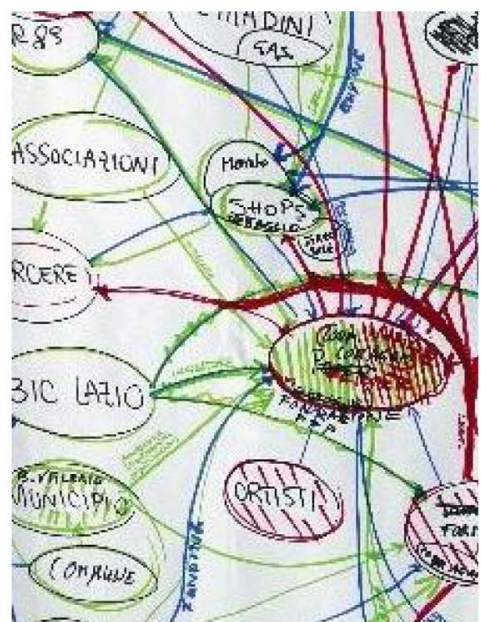

Theme A - Economy + gov

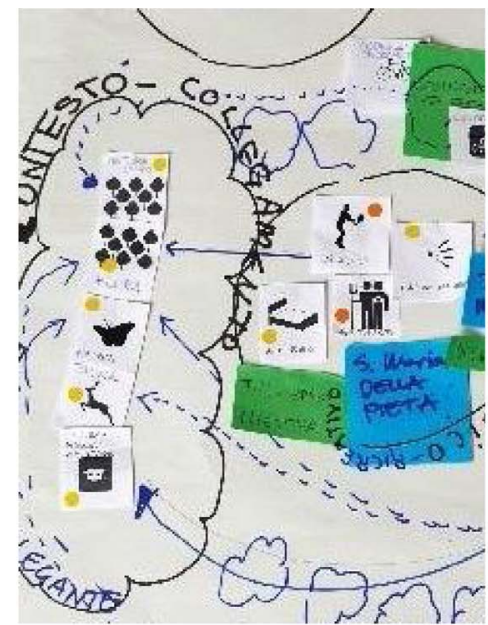

Theme B - Urban integration

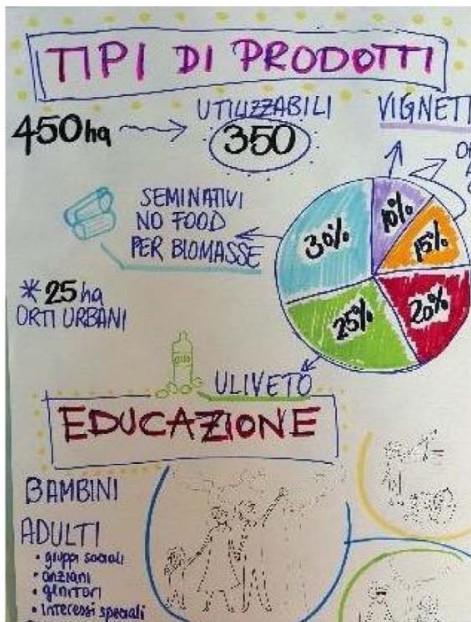

Theme C - Agriculture

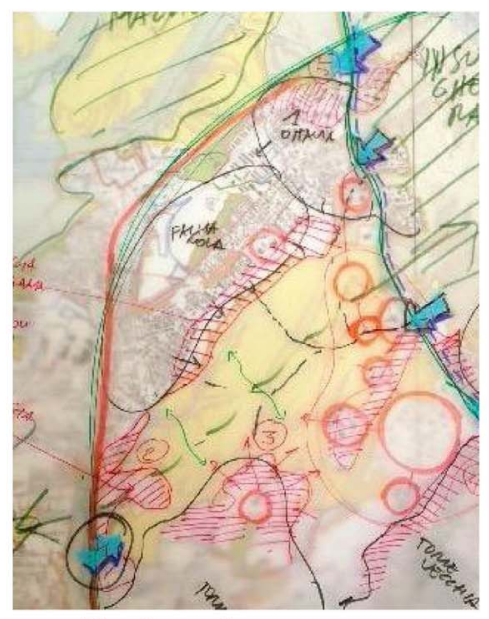

Theme D - Landscape

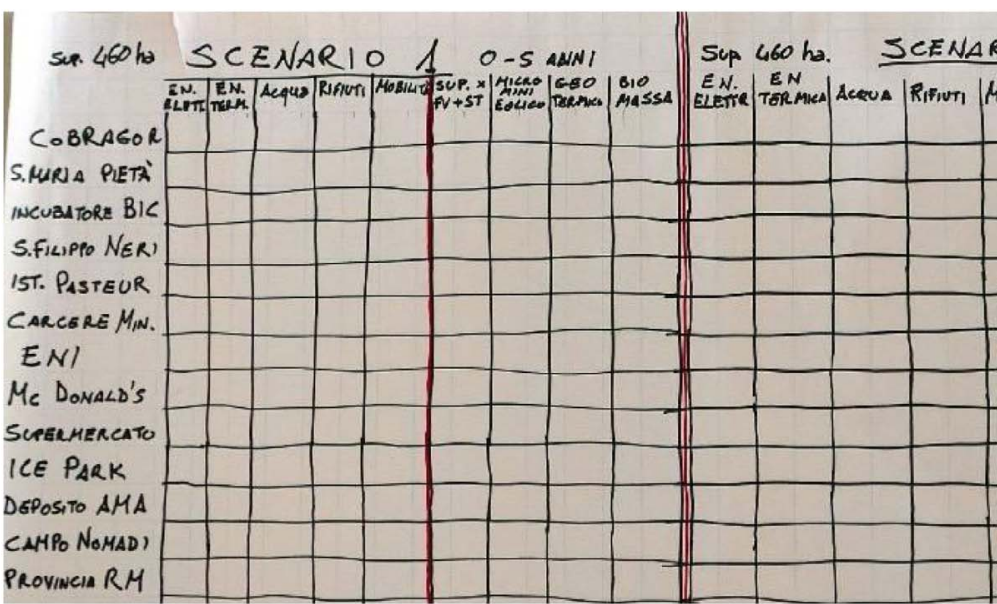

Theme E - Energy and resources

Fig. 4. Examples of the styles of the maps produced for the final exhibition.

earlier: meaning, actors and scale. The workshop involved five groups, each investing three days of the workshop to explore their respective themes. Four of the groups arrived at successful outcomes. In the following section, qualitative results are discussed (Table 2).

Applying the curatorial approach resulted in a leveraging of previously entrenched positions and a significant shift in perspective, notably, towards optimism and common purpose. Looking at the findings from a written report from the NGO that physically hosted the event, questionnaires distributed by the authors and a report by a social psychologist observing the workshop, there is ample evidence that points to a real shift in attitude and thinking about the Parco. The findings from the social psychologist's report state:

"this collective formula of vision-making has created the foundation to build a collectivity of meaning, a grid of not only interpretive but also of co-constructive and co-productive ideas, projects, visions. These visions had the common denominator of the necessity for a project-oriented change in the current way of life related to this site." (translation by author)

On a close analysis of the various reports and questionnaires, it becomes evident that a sense of collective identity and purpose was developed. Despite multiple mentions by participants of the difficulties and complexity of enacting real change, particularly when bridging multiple institutions, the answer to this came in the shape of 'collective action' without mentioning particular tools or strategies. "Individual action for individual interests," according to several participants, "is what created the problem in the first place", the answer to this was a social coalescence around the Parco.

Along with this optimism, many of the proposed concrete solutions remain obtuse and at the ideation stage. Despite efforts to have participants explore practical solutions based in systems thinking, the impact most pronounced was an excitement about possibilities, "many enthusiastically declared their willingness to participate in the project and its initiatives" claimed the social 
Table 2

Box of results.

\begin{tabular}{|c|c|c|c|}
\hline Theme & Meaning & Actors & Scale \\
\hline $\begin{array}{l}\text { Governance } \\
\text { system(Map } \\
\text { A) }\end{array}$ & $\begin{array}{l}\text { This theme began as a focus on economic/ } \\
\text { financial issues while it later became clear } \\
\text { that without a clear plan and with more than } \\
\text { eight public and private landowners, the } \\
\text { governance of the site was critical. This } \\
\text { resulted in the development of a 'Community } \\
\text { Interest Company' (CIC). }\end{array}$ & $\begin{array}{l}\text { As this topic was so broad, there were vast } \\
\text { tensions between academic, entrepreneurs, } \\
\text { public actors and local residents within the } \\
\text { group. This tension proved to be useful in } \\
\text { strengthening the terms of reference for the } \\
\text { CIC such that it had representation and } \\
\text { buy-in from a vast range of actors. The } \\
\text { result was to define the most significant } \\
\text { leverage point in this story, namely finding } \\
\text { a way to engage with the local hospital. } \\
\text { This also allowed some guestimates in } \\
\text { terms of employment and revenue - } \\
\text { which appealed to the local land holders. }\end{array}$ & $\begin{array}{l}\text { It was clear that enormous tensions were } \\
\text { raised between the larger scale interests (or } \\
\text { disinterest) of the land owners and the drive } \\
\text { of the local residents and businesses. The } \\
\text { outcome resulted in defining the role of the } \\
\text { CIC in terms of bridging the gap between } \\
\text { adding value to the landowners while } \\
\text { appropriate access rights to local users. }\end{array}$ \\
\hline $\begin{array}{l}\text { Urban system } \\
\text { (Map B) }\end{array}$ & $\begin{array}{l}\text { Neighbourhoods once divided by the } \\
\text { agricultural land could turn their attention to } \\
\text { collective benefits (such as a crèche, } \\
\text { community space, location for education or } \\
\text { employment etc). The result was a map of } \\
\text { collective exploring five topics: places, } \\
\text { artefacts, activities, users/actors and } \\
\text { channels. It resulted in an abstract } \\
\text { architectural brief for rehabilitating } \\
\text { buildings on the site. }\end{array}$ & $\begin{array}{l}\text { The group looked at six dimensions to help } \\
\text { define what functions would relate to a } \\
\text { vast range of different actors. These } \\
\text { include work, support, learning, culture, } \\
\text { economics and gateways. Existing } \\
\text { buildings distributed across the site would } \\
\text { address a certain collection of such themes } \\
\text { and thus have a different character. }\end{array}$ & $\begin{array}{l}\text { The essential outcome was the ability to look } \\
\text { at the functionality of the site as a whole and } \\
\text { then distribute these functions down to the } \\
\text { available spaces on the site, which would } \\
\text { also have most impact on the } \\
\text { neighbourhoods they adjoined. }\end{array}$ \\
\hline $\begin{array}{l}\text { Landscape system. } \\
\text { (Map C) }\end{array}$ & $\begin{array}{l}\text { The landscape focus on nodes and links. The } \\
\text { site currently acts as a large green barrier } \\
\text { with very little formal access across it } \\
\text { allowing easy access to the likes of the } \\
\text { hospital, train station or shopping centre. } \\
\text { Meaning was gained through the landscape } \\
\text { experience moving through the site and how } \\
\text { the site could be connected with the larger } \\
\text { patchwork or green spaces. }\end{array}$ & $\begin{array}{l}\text { The challenge was that while the idea of } \\
\text { improving accessibility was foundational, } \\
\text { it may not be to the liking of private } \\
\text { owners. The result here was a masterplan } \\
\text { of paths that could allow gradual access to } \\
\text { private land. }\end{array}$ & $\begin{array}{l}\text { The landscape group resulted on an outcome } \\
\text { ensuring the larger masterplan could be } \\
\text { accommodated on the contours of the land. }\end{array}$ \\
\hline $\begin{array}{l}\text { Agricultural } \\
\text { system (Map } \\
\text { D) }\end{array}$ & $\begin{array}{l}\text { The food system was a challenge in terms of } \\
\text { making local agriculture relevant within an } \\
\text { urban context where there is a range of skills } \\
\text { and interests. The food system thus could } \\
\text { mean very different things for different } \\
\text { actors thus it resulted in the definition of } \\
\text { three main themes: the production, } \\
\text { consumption and learning/inclusive aspects } \\
\text { of the story. These three themes were not } \\
\text { mutually exclusive but mutually enforcing - } \\
\text { in other words eating local food would } \\
\text { provide interest in growing, education would } \\
\text { increase production, while local production } \\
\text { results in a larger customer base. }\end{array}$ & $\begin{array}{l}\text { The agricultural system could respond to a } \\
\text { large range of actors depending on interest } \\
\text { and commitment allowing for a } \\
\text { categorisation of four types of spaces: } \\
\text { allotment, collective, cooperative and } \\
\text { commercial. The fact that both allotment } \\
\text { and a commercial garden existed on the } \\
\text { site provided a valid foundation for the } \\
\text { concept. }\end{array}$ & $\begin{array}{l}\text { Scale here was explored in terms of the size } \\
\text { of the agricultural production system, its } \\
\text { location and its impact. Naturally the } \\
\text { allotment gardens were very attractive to the } \\
\text { large number of neighbours that do not have } \\
\text { a garden, however allotments would have } \\
\text { only a certain level of impact on production } \\
\text { scale and communicating the virtues of the } \\
\text { agricultural system. The result was a } \\
\text { mapping of where certain types of } \\
\text { agricultural spaces would occur and possible } \\
\text { production estimated at } 350 \text { ha of arable } \\
\text { land. }\end{array}$ \\
\hline
\end{tabular}

psychologist. The curatorial approach, it appears created a considerable attachment to the Parco both individually and collectively. The sense of 'meaning' is palpable in the interviews; the Parco is the locus for possibilities albeit without being overtly explicit. Based on her interviews with the participants on the future of the Parco, the social psychologist identified six key themes: activism, change in lifestyle, wellness, trust, collectivity and diffusion. These may appear trivial but they can also be interpreted as a significant transformation given the decades of inaction, general scepticism of large-scale change and a myriad of competing interests.

\section{Reflection and conclusion}

The curatorial approach developed in this paper addresses wicked problems through two complementary strategies. First, by rethinking the role of planning professionals as "curators" whose interventions are guided by the principles of creating meaning, caring for the context, fostering diverse ways of knowing, and oscillating between the particular and the whole. The curatorial here provides a unique set of instruments for dealing with different knowledge parcels as well as a useful metaphor for thinking of the role of the planner in ecological projects-as a caretaker and guardian. Secondly by embedding the curatorial approach in a system perspective, actors are encouraged to simultaneously think in terms of individual and structural actions that are necessary for sustainability transitions. In the case of our work in Rome, the combination of these two strategies led us to develop a curatorial cycle, which offers an example for planners to navigate through the different steps involved in real-world system transitions.

The curatorial cycle resulted in a renewed interest and engagement with the context. The focus on meaning and signification 
enabled diverse and often conflictual actors to come together and develop dialogue, rooting the discussions at a deeper level than the individual's interest or their position. After several decades of intractable negotiations and deadlock, actors were able to come together and develop new strategies for the peri-urban asset, such as a 'Community Interest Company', which bridged the gap between landowners and local users. The continuum between linear systems thinking and experiential or mimetic thinking brought concrete discussions in line with a sense of attachment, positivity and a prospect of real change. The positivity and sense of meaning experienced at the workshop, we argue, integrates the realm of possibility with a critical examination of the context through a systems approach. The artefacts, which were co-created and later exhibited to the public on the final day, were impregnated with the personal and collective search for a solution to a problem that had hitherto been perceived as "inaccessible and impossible". While this is not a concrete outcome, it is an important part of the possibility for change, a shared sensibility rooted in a deep sense of individual and collective signification.

The paper demonstrates that framing urban planning situations as wicked problems and adopting a curatorial approach with systems at its heart, provides considerable mileage for untangling stand-offs and making such problems accessible to relevant actors. In effect, this implies a re-framing of the role of facilitator as a creative knowledge broker, mediating, translating, positioning and choreographing different types of knowing. It provides new modes of action for the transition researcher as not only an analyst and facilitator of frontrunner-driven experiments but also for providing the conditions and interpretations for signification.

Given the considerations of subjectivity and involvement of the curator, it seems important that participants and organisers of curatorial approaches like the one whose application was outlined in this paper be aware of the limits and overall orientation of the approach. Planner-curators should be transparent about the fact that the design of a curatorial workshop entices a feeling of collectivity, belonging and meaning, without predefining what particular content the participants will project into that meaning. The buy-in from participants that the curatorial approach appears to achieve might come at the expense of the advantages of more specialised and individualistic forms of planning. This being said, while technocratic processes and disciplinary fragmentation are widespread in real-world planning situations, especially if they happen at the scale of large projects such as the one presented in this paper, the thrust and momentum of meaningful collective experience are important to initiate (Metzger 2013) but often completely missing. In projects in which meaningful engagement of a large variety of actors is important, the curatorial appears to be a vital tool for complementing more conventional planning tools.

Additionally, the posture of a 'guardian' or 'caretaker' that the planner adopts in the curatorial is subject to important caveats and potential pitfalls that shouldn't be underestimated. Given the ability of the curator to elicit and stimulate meaning, it seems important that the client (or community) of a curatorial planning process becomes familiar with the normative worldview of the curator so that they understand in which way he or she might steer the discussion.

The workshop was perceived to be a 'success' by not only the hosting NGO but also by the funding body, the Business Innovation Centre of the Region of Lazio, which soon afterwards commissioned a similar workshop for another problematic site in the region. Reflecting on next steps for the curatorial approach, we recognise certain limitations when dealing with such high levels of complexity-particularly when identifying practical steps forward in the context of specific processes, including when and how to pass the baton from the role of the curator to other roles, which can guide the process further.

Local communities, especially in Southern Europe, experience the confluence of fiscal austerity, environmental degradation and social tensions. These crises, however, also release financial, physical and human resources that were so far oriented towards business-as-usual approaches for assets such as public land, vacant real estate or defunct industrial sites. While the integration of such assets into community-based initiatives is becoming an increasingly popular strategy with policy makers and civil society organisations interested in sustainability, we observe narrow and shallow approaches for engaging with the complex and conflictual nature of the 'wicked problems' that such transitions typically imply. This paper contributes to filling this gap by presenting the theoretical and empirical basis of what we call a curatorial approach aimed at locally grounded system transitions.

We have applied this new approach in the context of the development of the Parco Agricolo Casal del Marmo, a site of undeniable economic, environmental and social potential situated in the periphery of Rome. The empirical evidence demonstrates that our approach allows for actors to effectively address the complex and conflictual nature of sustainability transitions. Actors notably felt empowered to make meaningful contributions to the transition of the site towards becoming a hub of a community-based food system and felt confident that the inevitable fuzziness of the transition process could be overcome by aligning all actors through a strong common vision. This is a first large-scale application of the curatorial approach; further empirical testing is nevertheless warranted so as to assess its external validity in other contexts.

\section{Funding}

This research is part of the TURaS and TRADERS project and received funding from the European Union's Seventh Framework Programme for research, technological development and demonstration under grant agreement No 282834 and 608299 , respectively.

\section{References}

Acord, S.K., 2010. Beyond the head: the practical work of curating contemporary art. Qual. Sociol. 33 (4), $447-467$.

Albrechts, L., 2013. Reframing strategic spatial planning by using a coproduction perspective. Plann. Theory 12 (1), $46-63$.

Associazzone Comitato per il Parco di Casal del Marmo, 2012. Idee Progetto per il Parco Agricolo Casal del Marmo, 20 Novembre 2012. Associazzone Comitato per il Parco di Casal del Marmo, Rome (31 p.).

Barles, S., 2015. The main characteristics of urban socio-ecological trajectories: Paris (France) from the 18th to the 20th century. Ecol. Econ. 118, 177-185.

Bollettino Ufficiale della Regione Lazio, 2014. Legge Regionale, n12 del 13 agosto 2011, Numero 86, Supplemento n 1, 149p. 
Brown, J.S., Duguid, P., 2001. Knowledge and organization: a social-practice perspective. Organ. Sci. 12 (2), 198-213.

Brown, V.A., Harris, J.A., Russell, J.Y., 2010. Tackling Wicked Problems Through the Transdisciplinary Imagination. Earthscan.

Buchanan, R., 1992. Wicked problems in design thinking. Des. Issues 5-21.

Checkland, P., Scholes, J., 1990. Soft Systems Methodology in Action. John Wiley \& Sons, Chichester.

Churchman, C.W., 1967. Guest Editorial: Wicked Problems.

Cox, V., Goethals, M., De Meulder, B., Schreurs, J., Moulaert, F., 2014. Beyond design and participation: the 'Thought for Food’ Project in Flanders, Belgium. J. Urban Des. 19 (4), 412-435.

Dahdul, W.M., Balhoff, J.P., Engeman, J., Grande, T., Hilton, E.J., Kothari, C., Westerfield, M., 2010. Evolutionary characters phenotypes and ontologies: curating data from the systematic biology literature. PLoS One 5 (5), e10708.

Dietz, T., Ostrom, E., Stern, P.C., 2003. The struggle to govern the commons. Science 302 (5652), 1907-1912.

Eeds, M., Peterson, R., 1991. Teacher as curator: learning to talk about literature. Reading Teacher 45 (2), 118-126.

Fischer-Kowalski, M., Rotmans, J., 2009. Conceptualizing, observing, and influencing social-ecological transitions. Ecol. Soc. 14 (2), 3.

Frantzeskaki, N., Broto, V.C., Coenen, L., Loorbach, D. (Eds.), 2017. Urban Sustainability Transitions. Routledge.

Gallagher, K., Wessels, A., 2013. Between the frames: youth spectatorship and theatre as curated, 'unruly'pedagogical space Research in Drama Education. J. Appl. Theatre Perform. 18 (1), 25-43.

Geels, F.W., Schot, J., 2007. Typology of transition pathways in sociotechnical systems. Res. Policy 36 (3), 399-417.

Gherardi, S., Nicolini, D., 2000. To transfer is to transform: the circulation of safety knowledge. Organization 7 (2), 329-348.

Glasner, J.D., Rusch, M., Liss, P., Plunkett, G., Cabot, E.L., Darling, A., Perna, N.T., 2006. ASAP: a resource for annotating, curating, comparing, and disseminating genomic data. Nucleic Acids Res. 34 (suppl. 1), D41-D45.

Goble, C., De Roure, D., 2008. Curating scientific web services and workflows. Educause Rev. 43 (5).

Hamdouch, A., Moulaert, F., 2006. Knowledge infrastructure, innovation dynamics, and knowledge creation/diffusion/accumulation processes: a comparative institutional perspective. Innovation: Eur. J. Soc. Sci. Res. 19 (1), 25-50.

Head, B.W., Alford, J., 2015. Wicked problems implications for public policy and management. Admin. Soc. 47 (6), 711-739.

Hill, D., 2012. Dark Matter and Trojan Horse, a Strategic Design Vocabulary. Strelka Press.

Kaethler, M., 2016. THE CURATORIAL navigating knowledge boundaries. Mediations: Art and Design Agency and Participation in Public Space. RCA, London (November).

Kaszynska P, Parkinson J and Fox W., 2012. Re-thinking Neighbourhood Planning: From consultation to collaboration ResPublica Green Paper.

Kemmis, S., McTaggart, R., 1988. The Action Research Planner. Hyperion, New York.

Khan, A.Z., Moulaert, F., Schreurs, J., 2013. Epistemology of space: exploring relational perspectives in planning, urbanism, and architecture. Int. Plann. Stud. 18 (3-4), 287-303.

Khan, A.Z., Moulaert, F., Schreurs, J., Miciukiewicz, K., 2014. Integrative spatial quality: a relational epistemology of space and transdisciplinarity. Urban Design Plann. 393-411.

Kindon, S., Pain, R., Kesby, M., 2007. Participatory Action Research: Origins, Approaches and Methods. Oxon, Routledge.

Lave, J., Wenger, E., 1991. Situated Learning: Legitimate Peripheral Participation. Cambridge university press.

Lind, M., von Bismarck, B., Cohen, A.P., Gillick, L., Wood, B.K., Zolghadr, T., 2010. In: Wood, B.K. (Ed.), Selected Maria Lind Writing. Sternberg Press.

Loeckx, A., 2004. Urban trialogues: visions, projects co-productions. Un-Habitat 21.

Loorbach, D., Wittmayer, J.M., Shiroyama, H., Fujino, J., Mizuguchi, S., 2016. Governance of Urban Sustainability Transitions. Springer.

Loorbach, D., 2007. Transition Management: New Mode of Governance for Sustainable Development. International Books.

Lynn, David J., et al., 2010. Curating the innate immunity interactome. BMC Syst. Biol. 41, 1.

Martinon, J.P., 2013. The Curatorial: A Philosophy of Curating A and C Black.

Metzger, J., 2013. Placing the stakes: the enactment of territorial stakeholders in planning processes. Environ. Plann. A 45 (4), $781-796$.

Miciukiewicz, K., Moulaert, F., Novy, A., Musterd, S., Hillier, J., 2012. Introduction: problematising urban social cohesion: a transdisciplinary endeavour. Urban Stud. 49 (9), 1855-1872.

Midgley, M., 1991. Wisdom, Information, and Wonder: What Is Knowledge For? Psychology Press.

Mitlin, D., 2008. With and beyond the state-co-production as a route to political influence, power and transformation for grassroots organizations. Environ. Urban. 20 (2), 339-360.

Moulaert, F., Schreurs, J., Van Dyck, B., 2011. Reading space to address spatial quality. In: SPINDUS Conference, Spatial Innovation Planning Design and User Involvement. Leuven, Belgium.

Moulaert, F., Van Dyck, B., 2013. Framing social innovation research: a sociology of knowledge perspective, chapter 35. In: Moulaert, F., MacCallum, D., Mehmood, A., Hamdouch, A. (Eds.), International Handbook on Social Innovation. Edward Elgar.

O'Neill, P., 2012. The Culture of Curating and the Curating of Culture (s). MIT Press.

O'Neill, P., Wilson, M., 2010. Curating and the Educational Turn Open Editions and De Appel.

Obrist, H.U., Lamm, A.E., 2011. Everything You Always Wanted to Know About Curating but Were Afraid to Ask. Sternberg Press.

Ostrom, E., 1996. Crossing the great divide: coproduction, synergy, and development. World Dev. 24 (6), 1073-1087.

Rittel, H.W.J., Webber, M.M., 1973. Dilemmas in a general theory of planning. Policy Sci. 4, 155-169.

Rotmans, J., Kemp, R., van Asselt, M.B.A., 2001. More evolution than revolution: transition management in public policy. Foresight 3 (1), 15-32.

Rubin, D.L., 2008. Creating and curating a terminology for radiology: ontology modeling and analysis. J. Digit. Imaging 21 (4), 355-362.

Segers, R., Van den Broeck, P., Khan, A.Z., Moulaert, F., Schreurs, J., De Meulder, B., Miciukiewicz, K., Vigar, G., Madanipour, A. (Eds.), 2013. Manual for Spatial Quality Consulting the Genius of Places, Brussel. ASP, Brussel.

Smith, T.E., 2013. Thinking Contemporary Curating. Independent Curators International, New York, pp. 249-258.

Spangenberg, J.H., Omann, I., Hinterberger, F., 2002. Sustainable growth criteria: minimum benchmarks and scenarios for employment and the environment. Ecol. Econ. 42 (3), 429-443.

Suchiarelli, C., 2002. Paessagio a nord-ovest Risanamento ambientale e realizzazione di un'area naturalistica a Casal del Marmo Rome: Comune di Rome, 146p.

Swyngedouw, E., 2005. Governance innovation and the citizen: the Janus face of governance-beyond-the-state. Urban Stud. 42 (11), $1991-2006$.

Syed-Ikhsan, S. Omar Sharifuddin, Rowland, F., 2004. Knowledge management in a public organization: a study on the relationship between organizational elements and the performance of knowledge transfer. J. Knowl. Manag. 8 (2), 95-111.

Thompson, C., 2005. Making Parents: The Ontological Choreography of Reproductive Technologies. MIT press, Cambridge, Mass.

Van den Broeck, P., 2011. Analysing Social Innovation Through Planning Instruments: A Strategic-Relational Approach Strategic Spatial Projects Catalysts for Change. pp. 52-78.

Webb, A.M., Linder, R., Kerne, A., Lupfer, N., Qu, Y., Poffenberger, B., Revia, C., 2013. Promoting reflection and interpretation in education: curating rich bookmarks as information composition. In: Proceedings of the 9th ACM Conference on Creativity and Cognition. ACM, June. pp. 53-62.

Weber, E.P., Khademian, A.M., 2008. Wicked problems, knowledge challenges, and collaborative capacity builders in network settings. Public Adm. Rev. 68 (2), $334-349$.

Witt, M., Carlson, J., Brandt, D.S., Cragin, M.H., 2009. Constructing data curation profiles. Int. J. Digital Curation 4 (3), 93-103. 